
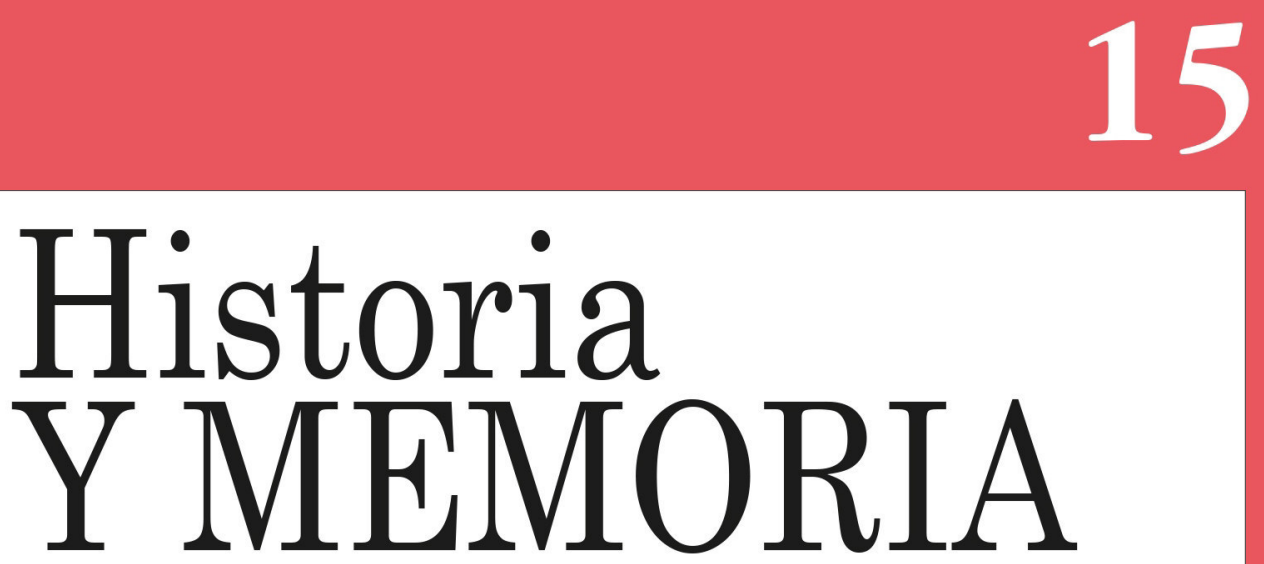

ISSN: 2027-5137 Julio - Diciembre, Año 2017 - Tunja, Colombia

El papel del Estado colombiano en la conformación del sector siderúrgico de Boyacá. 1938-1980

https://doi.org/10.19053/20275137.n15.2017.5568

Patricia Carolina Barreto Bernal orcid.org/0000-0001-5349-9712

Juan Carlos Jurado Jurado orcid.org/0000-0003-1665-0553

Páginas: 203-242

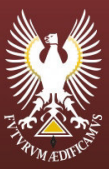




\title{
El papel del Estado colombiano en la conformación del sector siderúrgico de Boyacá. 1938-1980*
}

\author{
Patricia Carolina Barreto Bernal ${ }^{1}$ \\ Universidad Pedagógica y Tecnológica de Colombia \\ Juan Carlos Jurado Jurado ${ }^{2}$ \\ Universidad EAFIT - Colombia
}

Recepción: 09/11/2016

Evaluación: 02/05/2017

Aprobación: 31/05/2017

Artículo de Investigación e Innovación.

https://doi.org/10.19053/20275137.n15.2017.5568

\section{Resumen}

En este artículo se expone el papel del Estado colombiano en la conformación del sector siderúrgico del Departamento de Boyacá, entre 1938 y 1980. El intervencionismo del Estado colombiano ha sido un elemento fundamental para la

* El Presente artículo hace parte de los resultados de la investigación de tesis de Doctorado en Administración de la Universidad EAFIT titulada: "Conformación del empresariado del sector siderúrgico y su papel en los procesos de modernización social, económica y administrativa en el corredor industrial de Boyacá. 1960 -1990». La cual fue defendida y tuvo reconocimiento Cum Laude por parte del tribunal de evaluación.

1 Doctora en administración (Universidad EAFIT). Investigadora del grupo de investigación «Proyectos Organizacionales para el Desarrollo Empresarial de la Región»; Líneas de investigación: Esquemas y modelos de productividad y competitividad, Estrategia y Estructura de Gestión Empresarial, Perfiles y características del Empresario Boyacense. Gestión de la innovación y Transferencia de Tecnología. Publicación reciente: Coautora de «Diagnóstico de competitividad del sector productor de arracacha. Caso municipio de Boyacá (Colombia) 2014». Apuntes del CENES 35, n 62 (2016): 245-278. $\square$ patricia.barreto@uptc.edu.co

(iD orcid.org/0000-0001-5349-9712

2 Doctor en Historia (Universidad de Huelva España). Docente Universidad EAFIT, Investigador del grupo de investigación «Historia Empresarial» de la misma universidad; línea de investigación: Historia Empresarial Regional. Publicación reciente: «Guerra y Nación. La guerra civil colombiana de 1851». HiSTOReLo. Revista de Historia Regional y Local 7, n 14 (2015): 99-140.凶jjurado@eafit.edu.co

(iD orcid.org/0000-0003-1665-0553 
sustitución de importaciones explicable por las condiciones endógenas y exógenas de la economía nacional durante la Segunda Guerra Mundial (1939-1945). Se parte de la hipótesis de que el Estado es la forma política que ha adoptado el sistema económico capitalista y por tanto el intervencionismo estatal en la economía es característica del proceso de modernización que se experimentó en Colombia entre finales del siglo XIX y principios del siglo XX. Se abordan las políticas y leyes estatales del sector siderúrgico, las instituciones estatales y gremiales que lo desarrollaron, el declive del intervencionismo y el surgimiento de siderúrgicas privadas. Se consultaron fuentes secundarias, prensa nacional, la revista oficial del gremio durante las décadas de 1960 y 1970 y CONPES.

Por último, es de resaltar algunos puntos clave que se encuentran fuera del alcance del presente estudio como lo son la interrelación del sector siderúrgico con otros sectores y los flujos de conocimiento y tecnologías nacionales e internacionales que se requerían para el montaje de grandes empresas; ideas vitales para generar nuevos procesos investigativos.

Palabras Clave: Intervención del Estado, industria siderúrgica, sustitución de importaciones, políticas de industrialización.

\section{The Role of the Colombian State in the Formation of the Steel Industry in Boyacá. 1930-1980}

\section{Summary}

This study presents the role of the Colombian State in the formation of the steel industry in the department of Boyacá, between 1933 and 1980. The interventionism of the Colombian State has been a fundamental element for import substitution, which may be explained by the endogenous and exogenous conditions of the national economy during World War II (1939-1945). We start from the hypotesis that the State is a political form which has adopted the capitalist economic system; for this reason State interventionism in 
economy is a characteristic of the process of modernization experienced in Colombia between the end of the XIX century and the beginning of the XXth. We take into account the state policies and laws regarding the steel industry, the State institutions and trade unions that developed this sector, the decline of interventionism, and the emergence of the private steel companies. Secondary sources consulted were national press, the official trade union journal between 1960 and 1970, and CONPES (the Colombian Council of Social and Economic Policies).

Lastly, we emphasize certain key points that are beyond the limits of the present study, such as interrelation between the steel industry and other sectors and knowledge areas, and the national and international technologies required for the activaton of great industries; vital ideas that may generate new research processes.

Key Words: State Intervention, Steel Industry, Import Substitution, Industrialization Policies.

\section{Le rôle de l'État colombien dans la formation du secteur sidérurgique du Département de Boyaca, 1938-1980}

\section{Résumé}

Dans cet article nous cherchons à préciser le rôle joué par l'Etat colombien dans la création du secteur sidérurgique du Département de Boyacá entre 1938 et 1980. L'interventionnisme de l'Etat colombien a été un élément fondamental de la substitution aux importations, qui s'explique à la fois par des conditions endogènes et exogènes de l'économie nationale pendant la Deuxième Guerre Mondiale (1939-1945). Notre hypothèse de départ c'est que c'est l'État la forme politique qui a adopté le système économique capitaliste et que l'interventionnisme étatique dans l'économie est une caractéristique du processus de modernisation expérimenté par la Colombie entre la fin du XIX ${ }^{\mathrm{e}}$ et le début du XX ${ }^{\mathrm{e}}$ siècle. Dans le texte, nous examinons les politiques et la législation du 
secteur sidérurgique, les institutions étatiques et corporatives qui l'ont développé, le déclin de l'interventionnisme et le surgissement des sidérurgies privés. Pour ce faire, nous avons consulté des sources secondaires, la presse nationale, le magazine officiel du secteur sidérurgique pendant les années 1960 et 1970 et les CONPES.

Enfin, nous tenons à souligner que quelques élémentsclé du sujet se trouvent au-delà du but de notre enquête : ainsi le rapport entre le secteur sidérurgique et d'autres secteurs, et les échanges de connaissances et de technologies nationales et internationales nécessaires pour la création de grandes entreprises. Ce sont, à n'en pas douter, des idées essentielles pour des recherches à venir.

Mots-clés: Intervention de l'État, industrie sidérurgique, substitution d'importations, politiques d'industrialisation.

\section{Introducción}

Historiadores económicos como Bejarano, Ocampo y Kalmanovitz ${ }^{3}$ coinciden en señalar que desde principio del siglo XX, Colombia desarrolló un ciclo de crecimiento económico orientado a la producción de bienes que hasta entonces eran importados. La conquista del empresariado nacional de la demanda de bienes atendida por productores extranjeros constituyó la "sustitución de importaciones», de modo que después de la Segunda Guerra Mundial (19391945) se afianzó en la economía colombiana la sustitución de bienes de consumo no duraderos (alimentos, bebidas, tabaco, vestuario, calzado y muebles) y de bienes intermedios (textiles, papel, caucho, llantas, minerales no metálicos). Fue hacia la posguerra que se gestó la sustitución de bienes de consumo duradero y de capital (productos metálicos, maquinaria eléctrica y no eléctrica y material de transporte) con las

3 Jesús Antonio Bejarano, «La economía colombiana entre 1946 y 1958», en Nueva Historia de Colombia, ed. Álvaro Tirado Mejía (Bogotá: Planeta, 1989), 149-166. José Antonio Ocampo, ed., Historia económica de Colombia (Bogotá, Colombia: T.M. Editores \& Fedesarrollo, 1994). Salamón Kalmanovitz, Economía y nación. Una breve historia económica de Colombia. (Bogotá: Grupo Editorial Norma, 2003) 
industrias del petróleo, química, automotriz, metalmecánica y siderúrgica. Así, la diversificación industrial fue un proceso continuo entre 1945 y 1974, durante el cual «las industrias de sustitución tardía pasaron de representar el 10.3\% del valor agregado industrial al 42.2\%». Las de sustitución temprana (bienes de consumo), por su parte, redujeron su participación en el mismo periodo del $62.4 \%$ al $35.9 \%{ }^{4}$. Fueron tan trascendentales las promesas de progreso mediante la industrialización, que esta se constituyó en toda una ideología nacional y en el eje del desarrollo y modernización del país ${ }^{5}$.

Tal proceso tenía raíces profundas como la emergencia de un mercado nacional auspiciado por la capacidad de demanda de la economía cafetera; la acumulación de capitales; la disponibilidad de mano de obra calificada y maleable a la vida fabril; la formación de una élite empresarial moderna; la adopción de las tecnologías provenientes de las revoluciones industriales de Estados Unidos y Europa; las coyunturas de guerra que bloquearon el comercio internacional, aprovechadas por el empresariado nacional y el intervencionismo estatal ${ }^{6}$. El propósito de este artículo, aborda el desarrollo del último aspecto en el contexto del sector siderúrgico y para ello es necesario reconocer que desde la década de 1930 el Estado colombiano tuvo un importante protagonismo en la conformación del sector siderúrgico nacional, en concordancia con las condiciones endógenas y exógenas señaladas anteriormente. Este dirigismo estatal posteriormente fue validado ideológicamente por la Comisión Económica para la América Latina - CEPAL (1948), que impartió un modelo de desarrollo basado en la sustitución progresiva de bienes industriales, considerada "como la única alternativa viable para los países en vía de desarrollo»? De igual forma se describen las relaciones del Estado y los

4 Ocampo, ed., Historia económica..., 273.

5 Ocampo, Historia económica..., Salomón Kalmanovitz, Nueva historia económica de Colombia, (Bogotá, Colombia: Taurus, 2010).

6 Alberto Mayor Mora, "Historia de la industria colombiana. 1886-1930», en Nueva Historia de Colombia, ed., Álvaro Tirado Mejía, (Bogotá: Planeta, 1989), 313332. Kalmanovitz, Economía y nación...

7 Ocampo, Historia económica..., 260. 
gremios, la vinculación de Colombia al Pacto Andino (1969), la recesión mundial de la industria siderúrgica de mediados de la década de los años setenta y la crisis económica de la siguiente en medio del desmonte del Estado y la liberalización de las importaciones.

El artículo, expresa parte de una investigación doctoral con un enfoque Cualitativo ubicado metodológicamente en la historia empresarial, utilizando como estrategia principal el análisis documental a partir de fuentes seriadas revisadas sistemáticamente como prensa, revistas gremiales y documentos normativos y legislativos. La investigación cuyos hallazgos parciales se exponen, es de tipo documental y se acude a la técnica del análisis de contenido de las fuentes secundarias y primarias ${ }^{8}$. Con una postura interpretativa desde la historia, la economía y la administración se proponen acercamientos descriptivos y explicativos de los temas analizados y se triangulan de manera crítica los diferentes niveles de significado de las fuentes, con objeto de lograr grados aceptables de validez y confiabilidad en las interpretaciones propuestas.

Se tomó como unidad de análisis el sector siderúrgico colombiano como uno de los escenarios que dejan ver con mayor claridad las intenciones de modernización industrial impulsadas por el Estado Colombiano, que aprovechando la dotación de recursos minerales inspiraron la creación de industrias pesadas con mayoría de capital estatal para jalonar

8 «Se suele llamar Análisis de contenido al conjunto de procedimientos interpretativos de productos comunicativos (mensajes, textos o discursos) que proceden de procesos singulares de comunicación previamente registrados, y que, basados en técnicas de medida, a veces cuantitativas (estadísticas basadas en el recuento de unidades), a veces cualitativas (lógicas basadas en la combinación de categorías) tienen por objeto elaborar y procesar datos relevantes sobre las condiciones mismas en que se han producido aquellos textos, o sobre las condiciones que puedan darse para su empleo posterior. El Análisis de contenido, de hecho, se convirtió a finales del siglo XX en una de las técnicas de uso más frecuente en muchas ciencias sociales, adquiriendo una relevancia desconocida en el pasado a medida que se introdujeron procedimientos informáticos en el tratamiento de los datos». José Piñuela, «Epistemología, metodología y técnicas del Análisis de Contenido" acceso el 23 de enero de 2012, http://anthropostudio.com/wp-content/ uploads/2015/04/Jos\%C3\%A9-Luis-Pi\%C3\%B1uel-Raigada.-Epistemolog\%C3\%ADametodolog\%C3\%ADa-y-t\%C3\%A9cnicas-del-an\%C3\%A1lisis-de-contenido.pdf 
procesos de desarrollo social y económico en zonas geográficas específicas. Sin embargo, con el tiempo, frente a las nuevas condiciones de mercado abierto se generó un cambio de dinámica económica en la que los empresarios privados debían enfrentar competitivamente las fuerzas del mercado y el Estado perdía su capacidad empresarial, dando un paso al lado para que fueran los gremios y empresarios privados quienes abanderaran los procesos de cambio tecnológico y de modernización. Este fue el efecto que tuvo Acerías Paz del Río como industria nacional en el sector Siderúrgico privado colombiano, a lo largo de la segunda mitad del siglo XX.

La estructura del artículo se planteó en el siguiente orden: en la primera parte se presentan brevemente los referentes teóricos y el debate historiográfico en el que se enmarcó el análisis; en la segunda, se describen los planes de gobierno y legislación que en la primera mitad del siglo XX fueron el marco que favoreció la consolidación de la industria siderúrgica como proyecto de modernización industrial en el país. En la tercera parte se presentan elementos que describen cómo la apertura de las importaciones abrió el paso a diferentes decisiones que configuraron la paulatina salida del Estado del sector siderúrgico en Colombia. En la cuarta parte se describe como FEDEMETAL, como gremio representativo de la industria siderúrgica nacional tuvo una intensa participación en la política pública del sector siderúrgico. En la quinta parte se explica cómo la industria Acerías Paz del Río influyó, de forma directa e indirecta, en el surgimiento de siderúrgicas privadas, que configuraron uno de los sectores de industria pesada más dinámicos pero a su vez vulnerables, en las últimas tres décadas del siglo XX. Finalmente se presentan las conclusiones y algunas propuestas de líneas de investigación futuras.

\section{Referentes teóricos y debate historiográfico}

En el debate historiográfico acerca del intervencionismo estatal, es necesario reconocer los planteamientos relacionados con la industrialización del país; al respecto Corchuelo y 
Misas $^{9}$, parten de la correlación entre la tasa de crecimiento del ingreso y la expansión de la industria originada por una mayor productividad como resultado de la división internacional del trabajo. Explican el crecimiento del sector industrial colombiano entre 1945 y 1958 como respuesta a la expansión de la demanda efectiva generada en otros sectores como el agrícola y el de servicios. Para Ocampo ${ }^{10}$, el «intervencionismo moderno» nació con la Reforma Constitución liberal de 1936, con objeto de racionalizar la producción, distribución y consumo de bienes y servicios, y de proteger los derechos de los trabajadores; este intervencionismo según el autor parte de la formación del Estado moderno ligado a la consolidación del capitalismo en Colombia, durante la segunda mitad del siglo XX. A diferencia del estructuralismo de Ocampo, para Bejarano el intervencionismo estatal colombiano se forjó en las apremiantes circunstancias de la Segunda Guerra Mundial, mediante una "economía de emergencia» que forzó al Estado a coordinar y controlar los transportes, el comercio y las importaciones adoptando los criterios de una «economía de guerra que fue más el fruto de las circunstancias que de nuevas concepciones sobre el papel del Estado en la economía, pero que en todo caso acabaron ampliando y fortaleciendo el radio de intervención gubernamental ${ }^{11}$. Por su parte, Gaviria $^{12}$, considera que el intervencionismo equivale a la política económica enmarcada en el modelo cepalino, que la clase dirigente acogió de manera unánime y supo adaptar a la coyuntura de un país integrado que requería de un Estado moderno.

Tal modelo tuvo vigencia entre los años de 1930 y 1967 , cuando se agotó el desarrollo industrial "hacia adentro», la industria fue incapaz de liderar la economía nacional, y surgió un modelo de desarrollo basado en las exportaciones y en la construcción de viviendas. Desde una perspectiva

$9 \quad$ Alberto Corchuelo, y Gabriel Misas, «El proceso de industrialización colombiano 1945/1958», Revista uno en dos, $n^{\circ} 4$ (1975): 48-86.

10 Ocampo, Historia económica..., 217-218.

11 Bejarano, «La economía colombiana...», 149-150.

12 Juan Gaviria, «La economía colombiana. 1858-1970», en Nueva Historia de Colombia, ed. Álvaro Tirado Mejía, (Bogotá: Planeta, 1989), 167-188. 
marxista, Kalmanovitz considera que el Estado y la política económica no son independientes del sistema productivo de modo que las situaciones de crisis presionaron la intervención consciente del Estado burgués para contrarrestar los efectos de la Gran Depresión (1929). La intervención estatal no surgió solo por razones económicas sino políticas de manera que la industrialización colombiana transcurrió con poca intervención estatal y «fue inducida más por razones económicas que políticas» ${ }^{13}$.

Para estudiar el proceso de industrialización desde la sustitución de importaciones, Misas $^{14}$ ha propuesto varias etapas que van desde finales del siglo XIX hasta la apertura económica de la década de 1990. La tercera etapa, entre 1951 y 1970, se caracterizó por el «auge del proceso de sustitución» a partir de medidas gubernamentales deliberadas que no eran del todo nuevas, como la elevación del arancel existente desde 1931 y que gravaba la importación de artículos objeto de producción nacional. De igual forma se impuso el control de cambios, una "política monetaria basada en el crédito de fomento" a las industrias y a la teoría de la dependencia de la CEPAL, que circuló con intensidad durante el período. Misas indica que el proceso de sustitución tuvo lugar a partir de la «alianza que se dio en el bloque de clases en el poder entre dos grandes fuerzası: de un lado los cafeteros que proveían la gran fuente de divisas provenientes de sus exportaciones y los principales usuarios de ellas: «los industriales que importaban materias primas, maquinaria y tecnología para el proceso de producción incipiente de la industria manufacturera». Estas facciones hegemónicas se beneficiaron de los denominados precios macroeconómicos: la tasa de cambio y la tasa de interés ${ }^{15}$.

El más reciente aporte al campo lo constituye un texto de historia económica latinoamericana, escrito por Bértola

13 Kalmanovitz, Economía y nación..., 307-308.

14 Gabriel Misas, «De la sustitución de importaciones a la apertura económica. La difícil consolidación industrial». En Desarrollo económico y social en Colombia. Siglo XX (Bogotá: Universidad Nacional de Colombia, 2001), 111-134.

15 Misas, «De la sustitución de importaciones...», 114. 
y Ocampo sobre El desarrollo de América Latina desde la independencia. Los autores sugieren que es más acertado hablar de "industrialización dirigida por el Estado» que de «industrialización por sustitución de importaciones», y que constituye un nuevo modelo de desarrollo que a pesar de la heterogeneidad de patrones regionales, fue característico de la segunda globalización: se implementó durante el periodo de transición, entre la Gran Depresión y la Segunda Guerra Mundial, y logró un evidente predominio entre la posguerra y la década de 1980. Los autores aducen varias razones para su propuesta conceptual al indicar que «no es una etiqueta muy útil porque las nuevas políticas iban mucho más allá de la sustitución de importaciones e involucraban un creciente papel del Estado en muchas otras esferas del desarrollo económico y social» ${ }^{16}$. Adicionalmente, el proteccionismo y la industrialización contaban con un inveterado pasado en el hemisferio, las economías nacionales no se orientaron exclusivamente a un desarrollo «hacia adentro» para atender la demanda interna, sino que también promovieron las exportaciones como fuentes de divisas y de financiamiento gubernamental en lo que se ha denominado el «modelo mixto», y que ya en la década de 1960 concibió la integración regional como elemento integral. Entre las estrategias implementadas por los Estados se cuenta la superposición de viejas y nuevas medidas como: la protección arancelaria y no arancelaria, tipos de cambio múltiples y racionamiento de divisas, bancos de desarrollo e inversiones en infraestructura, regulaciones en la asignación de créditos privados y de las tasas de interés, incentivos fiscales, inversiones en sectores industriales estratégicos, subsidios a los precios de insumos utilizados por estas mismas empresas, "leyes de similares» (que prohibían la importación de bienes que compitieran con la producción nacional) y normas para que dichas industrias compraran sus materias primas y bienes intermedios nacionales ${ }^{17}$.

16 Luis Bértola, y José Antonio Ocampo, El desarrollo económico de América Latina desde la independencia (México: Fondo de Cultura Editores, 2013), 191.

17 Bértola y Ocampo, El desarrollo económico de..., 199. 
No es posible referir el intervencionismo estatal sin reconocer los planteamientos de investigadores de la historia social y la sociología política como Anderson, Tilly y Hobsbawn ${ }^{18}$, acerca de la formación de los Estados nacionales en Occidente desde los siglos XVII y XVIII, proceso histórico en que se inscriben los países latinoamericanos. Ello ha significado la creación de complejos mecanismos de hegemonía y monopolización de diversos recursos militares, económicos, políticos y culturales que responden a la configuración de órganos de poder administrativo, unificados y centralizados que intervienen y regulan un territorio, su población y su economía. En el marco de la historiografía colombiana e internacional la hipótesis de trabajo que sustenta este artículo implica reconocer que el Estado moderno, propio de las sociedades occidentales, es la forma política que ha adoptado el sistema económico capitalista, de manera que los mecanismos de regulación e intervención del Estado en la economía y la sociedad son constitutivos del mismo y expresión estructural del sistema político e institucional que lo definen ${ }^{19}$. Este planteamiento supone una postura relacional (no de causalidad) entre Estado y Capitalismo en tanto sus transformaciones históricas recíprocas implican que el Estado hace al Capitalismo y el Capitalismo hace al Estado.

\section{Planes de gobierno y legislación del sector}

Las potestades constitucionales y la planeación han sido expresiones del intervencionismo estatal en Colombia desde la posguerra, bajo sus dos modalidades más características: la «intervención directa», consistente en que el Estado actúa como empresario, es decir, como productor o inversionista directo, y los «mecanismos de regulación macroeconómica», mediante los cuales incentiva o restringe las actividades económicas de

18 Perry Anderson, El estado absolutista (México: Siglo XXI Editores, 1982). Charles Tilly, Coerción, capital y estados europeos, 990-1990 (Madrid: Alianza Editorial, 1992). Eric Hobsbawn, Naciones y nacionalismo desde 1870 (Barcelona: Crítica, 2000).

19 En este sentido el enfoque estructural que se asume en el artículo es confluyente con el de Bértola y Ocampo, pues se reconocen las diversas esferas de intervención estatal, constitutivas del Estado mismo. Acá se precisa el intervencionismo en un sector de la economía. 
agentes privados ${ }^{20}$. Para el caso de la industria siderúrgica el Estado colombiano implementó las dos modalidades de forma simultánea. Los propósitos de industrialización de los gobiernos del periodo 1938-1980 se manifestaron a través de la legislación comercial y la planificación industrial, los planes nacionales de 1940 para fomentar la industria, y el plan indicativo del sector siderúrgico de 1979 para reestructurar la producción nacional del hierro y del acero. Estos dos planes marcaron el inicio y fin, respectivamente, del dirigismo estatal en el sector. Durante el periodo se fundaron organismos estatales, y se implementaron diferentes leyes y decretos de carácter tributario, fiscal, financiero y de comercio exterior, orientados a la promoción y protección de la industria nacional, que favorecieron la aparición de la primera siderúrgica integrada creada por el Estado, la Siderúrgica Nacional de Acerías Paz del Río (1948), localizada en el Departamento de Boyacá, al Nororiente del país y siderúrgicas privadas complementarias.

\subsection{Estado empresario y empresas siderúrgicas}

La primera ley que el Estado promulgó durante el siglo XX y que expresa su intención de hacer inversiones en el sector siderúrgico, fue la Ley 97 del 24 de agosto de 1938, que lo facultó para el establecimiento de fábricas productoras de hierro y acero, con asignación presupuestal por cuatro años para adquirir acciones en las tres primeras siderúrgicas que se establecieran en el país, y reclamó participación en las juntas directivas y su control. Esta norma fue emitida por el gobierno del presidente Alfonso López (1934-1938), con el apoyo de los parlamentarios antioqueños, que ya tenían el proyecto para la Industria Siderúrgica de Medellín, creada en $1938^{21}$. Adicionalmente, la ley preveía la autorización de créditos destinados a las siderúrgicas y a la conexión de las vías férreas nacionales con los lugares donde se instalaran las fábricas para transportar insumos y productos terminados con precios especiales para estas empresas. Posteriormente, bajo el gobierno de Eduardo Santos (1938-1942), se promulgó

20 Ocampo, Historia económica..., Kalmanovitz, Nueva historia..., 206-207.

21 Gabriel Poveda, Políticas económicas, desarrollo industrial y tecnología en Colombia, 1925-1975 (Bogotá: Editora Guadalupe, 1979), 114. 
la ley 54 de 1939 que revistió al presidente de la República para «conjurar, corregir o atenuar los efectos de la actual crisis mundial sobre la organización económica y fiscal del país, adopte las medidas necesarias (...) el fomento y defensa de las industrias» ${ }^{22}$. Este fue el escenario jurídico que sustentó el decreto 1157 de 1940 por el cual se adoptó un plan general para el fomento de las actividades económicas del país, y constituyó un hito en la historia de la industria nacional, pues además de orientar las actividades agrícola, ganadera y manufacturera, privilegió las industrias básicas y de primera transformación de materias primas nacionales, algo que la iniciativa privada no había podido desarrollar. Además, reguló la importación de materias primas susceptibles de ser reemplazadas por nacionales y dio directrices para las inversiones en los mencionados sectores. Es de particular importancia esta ley, dado que en su artículo 30 se estipulaba la creación del Instituto de Fomento Industrial -IFI-, efectuado en 1940 y cuyas funciones trascendieron el aporte de «capital de riesgo en empresas $»^{23}$.

Los entes del Estado encargados de articular la normatividad y la ejecución coordinada de lo dispuesto en la ley 54 fueron los ministerios de Relaciones Exteriores y de Hacienda y Crédito Público, y el de la Economía Nacional que se pronunciaron según la conveniencia para los gremios productores nacionales. También se consultaba el Consejo Nacional de Vías de Comunicación y la Comisión Nacional de Tarifas en lo referente al transporte y distribución del hierro de Paz del Río, lo cual expresa el interés gubernamental por proteger integralmente la industria nacional dada su vulnerabilidad a la competencia internacional. El IFI como sociedad anónima tenía facultades para crear empresas básicas

22 Federación Nacional de Cafeteros, Compilación Cafetera 1939-1951 (Bogotá: Editorial Argra), 52. Recuperado de: http://ufdc.ufl.edu/UF00076974/00001/4j. 52 .

23 Kalmanovitz, Nueva historia..., Principales empresas creadas por el IFI: Siderúrgica de Medellín (1938), Icollantas (1942), Siderúrgica Paz del Río (1948), Alcalis de Colombia (1952), Compañía Nacional de Fertilizantes (1952), Cementos Boyacá (1955), Monómeros Colombo-Venezolanos (1967), Siderúrgica del Pacífico (1967), Conastil (1969), Forjas de Colombia (1969), Sofasa (1969), Compañía Colombiana Automotriz (1973). 
y de primera transformación contempladas en el Plan de Fomento, cuya función principal fue la fundación y ensanche de nuevas industrias primarias y sirvió como intermediario para que el gobierno suministrara los fondos para el establecimiento de nuevas industrias básicas. El IFI suscribió acciones del $51 \%$ del capital en las empresas que creara (como Paz del Río), previos estudios técnicos. Por el decreto 1439 de 1940, también se definieron las industrias materia de atención y estudio preferencial por parte del gobierno, dando prioridad a la industria siderúrgica discriminada así: "En cuanto al beneficio de minerales de hierro, la producción de hierro de primera fundición y acero. Se consideran además como parte de esta industria las explotaciones complementarias indispensables, como las de minas de hierro, cal y carbón, la producción de coque, materiales refractarios, etc. $\nu^{24}$.

En segundo renglón de la lista se encontraban las industrias de tratamiento metalúrgico de minerales no férricos y metales livianos (aluminio) y sus industrias complementarias extractivas. Seguían las industrias de explotación de carbón, cerámica, soda y similares, ácido sulfúrico y otros productos de la industria química, y productos específicos, agrícolas y pecuarios. Dispuesto el andamiaje estatal descrito, la siderúrgica integrada nació cuando el gobierno nacional, por medio de la Ley 45 del 15 de diciembre de 1947, autorizó la constitución de la Empresa Siderúrgica Nacional de Paz del Río ${ }^{25}$. Como lo ha señalado Lopera ${ }^{26}$, el conjunto de disposiciones y acciones dispuestas por parte del Estado hasta aquí expuestas, indican que la política de fomento surgió ante la necesidad de que el Estado complementara la iniciativa privada, allí donde sus capitales no podían correr con altos riesgos y largos plazos, como sucedió con las siderúrgicas y metalmecánicas.

24 A. Silva y T. Caldas, Régimen Legal de la Industria en Colombia (Bogotá, Colombia: Minerva Ltda., 1956), 151.

25 Mediante la escritura pública número 4.410 otorgada en la Notaría n 4 de Bogotá el 17 de septiembre de 1948. «La explotación de Paz del Río no es solo posible sino necesaria», El Tiempo, Bogotá, 11 de junio de 1948.

26 M. Lopera, El desarrollo de la Industria Metalmecánica Colombiana hasta 1970 (Medellín: Centro de Investigaciones Económicas Universidad de Antioquia. 1983), 31 . 


\subsection{Mecanismos estatales para la sustitución de importaciones}

En el marco constitucional que se generó entre 1945 y 1980, el Estado colombiano implementó mecanismos políticos y jurídicos orientados al desarrollo de la industria nacional, descritos a continuación.

Las compras oficiales. Fueron un mecanismo utilizado para que el hierro producido nacionalmente fuera proveído preferencialmente al Estado colombiano para los proyectos de urbanización, construcción de obras de infraestructura rural y urbana y de líneas férreas. Esta estrategia estaba contemplada en el Plan de Fomento de la Industria Nacional desde 1940 y se mantuvo así hasta 1965, cuando se inició una incipiente apertura de la economía nacional y de la entrada de materias primas más económicas traídas de Venezuela, bajo el Pacto Andino $^{27}$. Según el decreto 2894 de 1955 todas las entidades oficiales, semioficiales y los institutos y corporaciones de carácter público debían utilizar para la ejecución de las obras y contratos los productos de Paz del Río, a menos que esta no pudiera suministrarlos. Posteriormente, con la Ley 19 de 1982 se modificó el estatuto de compras nacionales, según anuncio del ministro de Desarrollo, que preveía la modificación del Decreto 150 de 1976 o Estatuto de Compras Oficiales: «pues cree que uno de los instrumentos más efectivos con que cuenta el Estado para fomentar la industria nacional es el de sus propias adquisiciones, prefiriendo en su contratación al empresario colombiano, dentro de niveles razonables de calidad y sin detrimento de los convenios y acuerdos internacionales» ${ }^{28}$. Esta política sufrió una reorientación hacia los años de 1980 en tanto se pasaba de la exclusividad concedida a la Siderúrgica a concederle la primera opción de compra como proveedor nacional, para los proyectos estatales con objeto de mitigar los efectos de la crisis internacional del

27 René De La Pedraja, Fedemetal y la industrialización de Colombia (Bogotá: Bogotá Fedemetal, 1986), 77-80.

28 Roberto Gerlein, «Estímulos a la actividad industrial» Carta Metalúrgica 352 (1982): 9 . 
acero y de los precios antidumping que afectaron notablemente las ventas del hierro y el acero nacional.

El control de las importaciones. Fueron el instrumento más utilizado entre 1945 y 1965, consistente en el impedimento a la entrada de proveedores extranjeros con la adopción de licencias previas y cuotas de importación. Se estipulaba que los proveedores aprobados complementaran la producción nacional y proveyeran maquinaria para la estructura industrial doméstica. El monto de los aranceles, la regulación de los precios, los subsidios directos e indirectos y las tasas de cambio preferenciales para ciertas importaciones, fueron muy usados por los gobiernos del periodo ${ }^{29}$.

Las reformas arancelarias de 1950, 1959 y 1964 fueron determinantes del crecimientoindustrial, dada su favorabilidad hacia la inversión fija en maquinaria y equipo ${ }^{30}$. En el sector siderúrgico, las políticas de restricción a las importaciones se evidenciaron a través de las medidas de absorción de chatarra de producción nacional con la resolución 595 de 1952 del Ministerio de Fomento, que prohibía su exportación mientras las siderúrgicas nacionales la compraran a un precio igual al de exportación. También la Resolución 182 de 1954, del mismo ministerio, con el fin de que el mercado nacional absorbiera toda la producción de Paz del Río, dictaminaba que la oficina de registro de cambios del Banco de la República se abstuviera de autorizar la importación de artículos de hierro y acero en bruto y en perfiles ${ }^{31}$.

Desde otro ángulo, la posición de los empresarios, fijada a través de la Federación Colombiana de Industrias Metalúrgicas, FEDEMETAL, fue pesimista sobre los controles arancelarios, pues en la medida en que avanzó el tiempo, la competencia internacional fue cada vez más abierta y agresiva, tendiente a movilizar la producción hacia las exportaciones. Hay que recordar que para los años

29 Álvaro Guarín y Daniel Franco, «La sustitución de importaciones como medio para un desarrollo sostenible», Revista Universidad EAFIT 44, n 51 (2008): 56-57.

30 Kalmanovitz, Nueva historia..., 208.

31 Silva y Caldas, Régimen Legal de..., 311. 
de 1960 y aun desde antes, en toda América Latina fueron más evidentes las limitaciones y contradicciones del modelo de sustitución, manifiestas en el desequilibrio en el balance comercial, el aumento de la inflación doméstica, los problemas monetarios y cambiarios, y la dualidad de desarrollo entre sectores favorecidos y los no favorecidos como la agricultura y las ingentes masas de pobladores urbanos. Ya desde 1949 los fundadores de la CEPAL habían advertido los problemas de buscar el desarrollo industrial a costa de otros sectores como la agricultura y las exportaciones de modo que se impulsó formalmente el ya citado "modelo mixto» y Colombia fue uno de los primeros en adoptarlo ${ }^{32}$. La normativa estatal que mejor revela esta política de fortalecimiento del sector externo es el decreto 444 de 1967, que:
[...] contemplaba diferentes medidas encaminadas a eliminar las restricciones que tradicionalmente habían obstaculizado el desarrollo del sector externo. Se estableció un sistema de ajustes graduales a la tasa de cambios [crawlingpeg] que reducía la incertidumbre introducida por las devaluaciones súbitas del pasado y daba las bases para seguir una política que garantizara permanentemente la competitividad de nuestras exportaciones en los mercados internacionales ${ }^{33}$.

Esta norma que expresa la necesidad de exponer la industria nacional a la competencia del mercado mundial contrastaba con la posición gremial. Por otra parte, el manejo de los aranceles como instrumento de protección industrial no fue de uso exclusivo de Colombia. En el escenario internacional se adoptó el Sistema General de Preferencias que tenía, entre otros propósitos ofrecerle a los países en desarrollo ventajas competitivas, derivadas del aprovechamiento de las rebajas arancelarias, incrementar y diversificar las exportaciones, fomentar su industrialización y acelerar su ritmo de crecimiento. Esta política preferencial hacia los países en

32 Pascual Amézquita, «La política de sustitución de importaciones en el contexto colombiano", Revista Globalización, Competitividad y Gobernabilidad, 2 (2010): 50. Gaviria, «La economía colombiana...»,170-173. Luis Garay, Estructura industrial e internacionalización en Colombia. 1967-1996, (Santafé de Bogotá: Departamento Nacional de Planeación, 1998), 29-30.

33 FEDEMETAL. «Evolución y perspectivas del modelo colombiano de industrialización», Carta Metalúrgica, 347 (1980a): 43. 
desarrollo se aprobó en 1968, con la Segunda Conferencia de las Naciones Unidas sobre Comercio y Desarrollo realizada en Nueva Delhi ${ }^{34}$.

Exenciones de impuestos. Se utilizaron para atraer inversionistas privados hacia proyectos en industrias básicas y complementarias que por el monto de las inversiones requeridas fueron menos atractivas que otras actividades con mayores rendimientos y menos inversión ${ }^{35}$. Entre las exenciones para la industria siderúrgica -Ley 14 de 1945, artículo $2^{\circ}$ - se contemplaba la exoneración del pago de impuesto sobre la renta, patrimonio y complementarios durante el periodo de montaje y los primeros diez años de producción. Luego de la creación de Paz del Río se expidieron nuevas leyes que contemplaban exenciones específicas para sus clientes, tales como la Ley 95 de 1948 (artículo 9) que otorgaba 20 años de exención de impuestos a la renta y complementarios y a excesos de utilidades a las industrias agregadas del hierro que utilizaran el $80 \%$ de la materia prima de la siderúrgica nacional. De igual forma se estimaba la exención de derechos de aduana sobre la importación de equipos y maquinaria para su puesta en marcha. La medida fue extensiva a las empresas colombianas que se dedicaran a la producción de hierro derivado de minerales extraídos del territorio nacional ${ }^{36}$. La Ley exoneraba por 20 años a Paz del Río del pago de todo impuesto, derecho o gravamen, nacional, departamental o municipal, del pago de derechos de aduana, consulares y de tonelaje o de cualquier impuesto de importación de equipos necesarios para el montaje de la planta.

El Departamento de Boyacá donde se localizaba Paz del Río, según el decreto 377 de 1954, también estableció la exención del pago de impuesto predial, por 20 años, a todos los inmuebles y maquinaria destinados al establecimiento de industrias derivadas de la Siderúrgica, así como al pago de

\footnotetext{
34 J. Gutiérrez, «La industria metalúrgica y metalmecánica frente al sector externo", Carta Metalúrgica, 334 (1976): 31.

35 «Se pide exonerar de impuestos a la Industria en Boyacá», El Tiempo, Bogotá, 03 de mayo de 1976.

36 Silva y Caldas, Régimen Legal de..., 17.
} 
impuesto municipales, de industria y comercio hasta $1959^{37}$. Posteriormente la Ley 81 de 1960, estableció exenciones tributarias por 10 años a industrias específicas que surgieron o se ampliaron, entre las que se contaban empresas de arrabio, acero, metales no ferrosos, fabricación de máquinas, herramientas y toda clase de industrias metalmecánicas usuarias de Paz del Río. Dicha ley estimuló además, la renovación de equipos para las empresas tradicionales.

Alternativas de financiamiento: ante las restricciones de capitales privados, fueron fundamentales para la sostenibilidad de las inversiones estatales y el surgimiento de empresas privadas que complementaran la producción siderúrgica nacional. En este sentido, con la creación del IFI el Estado colombiano inició acciones como inversionista directo, al fomentar y participar de la generación de nuevas industrias. Entre 1945 y 1954, las inversiones del sector público, pasaron de un $10 \%$ del PIB a más de un $30 \%$ a finales de la década de $1970^{38}$. En el accionar del IFI se contemplaba la consecución de recursos de crédito a través del Banco Interamericano de Desarrollo que debían ser previamente aprobados por el Consejo de Política Económica y Social -CONPES-, con objeto de financiar proyectos dirigidos a incrementar la producción de bienes manufacturados y desarrollar industrias de transformación de recursos y productos agrícolas, pesqueros, forestales y mineros. No obstante los ingentes esfuerzos que ello significó para el Estado colombiano, Kalmanovitz recuerda que no son nada comparables en profundidad ni en alcances a los casos de Argentina, Brasil o México; pero además hay que destacar que en Colombia, gran parte de la industrialización fue y ha sido "un proceso autóctono, realizado con capital colombiano y con escasa participación extranjera $»^{39}$.

Inversión extranjera: fue otra de las formas de financiamiento estatal que contribuyó al desarrollo tecnológico del país, en forma directa a través del Know-how, o indirecta,

$37 \quad$ Silva y Caldas, Régimen Legal de..., 120.

38 Kalmanovitz, Nueva historia..., 207-208.

39 Kalmanovitz, Nueva historia..., 197. 
con la importación de maquinaria. El financiamiento externo se generaba por aumento del capital o adquisición de una empresa ya existente ${ }^{40}$. En 1968 se creó el Fondo Financiero Industrial por la Junta Monetaria del Banco de la República, con el objeto de apalancar el capital de inversión de las empresas industriales, lo que sería trascendental para la coyuntura económica de la década de los años setenta, puesto que hasta 1967 la pauta de inversión del sector industrial se orientó, según el tamaño de la demanda interna, en las dos fases de industrialización que se habían presentado, la de bienes de consumo no durables y la de bienes intermedios y de capital. Como ya se indicó, el modelo de desarrollo nacional posterior a 1967 se orientó al comercio internacional, con la producción dirigida a mercados mayores que habían sido atendidos por importaciones, en donde era necesario reducir los costos y la necesidad de establecer un tamaño mínimo de las plantas, para poder establecer economías de escala con resultados eficientes ${ }^{41}$.

Por otra parte, para los empresarios del sector siderúrgico no era tan efectivo el papel que el Fondo Financiero desarrollaba, pues en 1976 denunciaron graves inconsistencias entre las políticas gubernamentales y los programas establecidos. Estas situaciones ponían en evidencia que la financiación otorgada por el Fondo no satisfacía las necesidades de los empresarios, lo que revela una inconsistencia del nuevo plan de desarrollo que podría haberse subsanado con fórmulas de asistencia técnica y crédito traducidas en un efectivo apoyo para el desarrollo de la pequeña y mediana industria del sector, y sobre todo para cumplir los cometidos del Plan: que las empresas del sector metalmecánico fueran generadoras de empleo, sustituir importaciones, abastecer bienes intermedios a la gran industria y su descentralización ${ }^{42}$.

40 «Documento CONPES» Bogotá, 1968, Departamento Nacional de Planeación (DNP). Bogotá-Colombia.

41 FEDEMETAL, «La intervención estatal de un peso muerto», Carta Metalúrgica, 385 (1980b): 21b.

42 M. Botero, «El sector desatendido», Carta Metalúrgica, 334 (1976): 49. 
Finalmente el gobierno creó mecanismos de financiación para Acerías Paz del Río al poner en manos del público y de inversionistas privados las acciones que en principio fueron propiedad del Estado, medida que expresa la relativa retirada del Estado empresario. La primera fuente de financiación fue el impuesto adicional sobre la renta y complementarios, con el que los contribuyentes tenían la facultad de adquirir acciones de la empresa estatal, por valor equivalente al impuesto equivalente al $2.5 \%$ con destino exclusivo a la Siderúrgica ${ }^{43}$. En este panorama, el crecimiento de la demanda nacional de productos de hierro, acero y metalmecánicos desde 1950, estructuró el sector metalmecánico con dos tipos de industrias: las nuevas, con plantas grandes y avanzada tecnología, que concentraban el mercado nacional y se especializaban en productos laminados y figurados para otras industrias, y empresas ya existentes que absorbían, subordinaban o se fusionaban con pequeñas plantas dedicadas a servicios complementarios para la industria siderúrgica, especializadas en actividades específicas ${ }^{44}$. Esta estructura oligopólica se conserva en la actualidad, con una alta participación de capital extranjero.

\section{Apertura de las importaciones y desmonte del Estado del sector}

Según Martínez, el Plan General de Desarrollo Económico y Social, 1960-1970, concibió un sistemático proceso de sustitución de importaciones liderado por el Estado, para lo cual fue condición ineludible la protección arancelaria y una política de estímulos crediticios ${ }^{45}$. Sin embargo, las transformaciones del contexto internacional con el dinamismo que cobraron los bloques económicos regionales, confluyeron en el viraje de la política económica y de comercio internacional del Estado colombiano, lo que afectó su relación con el sector siderúrgico.

\footnotetext{
43 Silva y Caldas, Régimen Legal de..., 311.

44 M. Lopera, El desarrollo de la Industria Metalmecánica..., 5.

45 Astrid Martínez, La Estructura arancelaria y las estrategias de industrialización en Colombia 1950-1982 (Bogotá: Universidad Nacional de Colombia. Centro de Investigaciones para el desarrollo, 1989), 117.
} 
En 1970 con el establecimiento del Pacto Andino como plataforma de unión aduanera entre Chile, Perú, Ecuador, Bolivia, Colombia y la posterior vinculación de Venezuela, se exigía que cada país aprovechara sus ventajas comparativas para desarrollar intercambios comerciales complementarios. Para entonces Colombia poseía más ventajas comparativas con la producción de carbón que con el hierro, pero aun así, veía una oportunidad de comercialización de este con los países vecinos, pues finalmente los integrantes del Pacto eran los principales compradores del hierro nacional con un 55.8\%, mientras que otros compradores con menor participación fueron: Panamá (10.1\%), Estados Unidos (9.3\%) y países de Europa, Centroamérica y la ALALC $(24.8 \%)^{46}$.

En 1976 el informe de Dastur Engineering, firma contratada por las Naciones Unidas en desarrollo del estudio Industria del Hierro y del Acero en Colombia, arrojó lineamientos sobre inversiones requeridas en cada una de las alternativas de desarrollo siderúrgico, tendientes a lograr la autosuficiencia nacional del orden del $80 \%$ para 1985 , costos de las importaciones requeridas para satisfacer la demanda y competitividad de la producción nacional en el área andina y de otros países ${ }^{47}$. Tal análisis permitió concluir que la producción nacional era competitiva en precios 1975, frente a la producción de los países del Pacto y de otros de mayor desarrollo.

En 1977 el expresidente Carlos Lleras (1966-1970) planteó que era necesario formular un plan indicativo en el que participara el Estado, la empresa privada y las agencias técnicas. Por ello desestimó la idea de un plan imperativo unilateral. En el mismo año, también se concretaron las intenciones de atender las demandas de materia prima de las empresas nacionales y fortalecer la industria siderúrgica de manera interinstitucional, con una visión de largo plazo que integrara políticas para empresas públicas y privadas en

46 Ocampo, Historia económica de..., 273.

47 Alternativas de Desarrollo del Sector Siderúrgico-Informe Dastur, 1976, Departamento Nacional de Planeación (DPN), DNP-1.344-UEI-IE, 1. 
materia siderúrgica ${ }^{48}$. En correspondencia con tal directriz, al año siguiente se creó el Consejo Nacional Siderúrgico mediante Decreto 2047 de 1978, integrado por representantes del más alto nivel y presidido por el Ministro de Desarrollo Económico. En este organismo tenían participación las entidades públicas relacionadas con el desarrollo del sector siderúrgico, representantes del sector privado y agremiaciones de productores y usuarios. En este marco institucional, el Estado estaría dispuesto a considerar esquemas de financiación convenientes, dirigidos a nuevas inversiones de empresas nuevas o existentes, incluyendo el grado y la forma de participación que le correspondería al Estado ${ }^{49}$. Así dispuesto, en 1979 el CONPES aprobó el Plan Indicativo de Desarrollo de la Industria Siderúrgica (PIIS) como resultado de las concertaciones logradas entre el gobierno y el sector privado, que estableció las bases para emprender los ensanches y nuevos proyectos siderúrgicos a fin de que Colombia pudiera autoabastecerse de acero en un $80 \%$ hacia 1985. El Plan incluía la producción de hierro esponja mediante una planta con capacidad de 350 mil toneladas de materia prima para las siderúrgicas semintegradas, de forma que incrementara su capacidad de producción y garantizara el abastecimiento de materias primas requeridas para su operación y así complementar la producción de Paz del Río, insuficiente para la demanda interna y las posibilidades de demanda externa derivadas del Pacto Andino ${ }^{50}$.

Como el Plan CONPES, contemplaba el abastecimiento de la demanda de acero originada en proyectos estatales, impedía las importaciones a precios de dumping, sin embargo, existió una gran brecha entre la intencionalidad del PIIS y sus resultados efectivos de mediano plazo, pues dirigentes del gremio denunciaron que no cesaban las importaciones que desplazaban un importante renglón del mercado nacional:

48 M. Méndez, «El papel potencial del sector metalúrgico», Carta Metalúrgica, 337 (1977): 31.

49 Plan Indicativo de la Industria Siderúrgica, noviembre, 1979, Departamento Nacional de Planeación (DNP), DNP-1 1609, 9-12.

50 M. Orduz, "La siderúrgica colombiana: un patrimonio nacional», Carta Metalúrgica, 352 (1982): 23. 
Corre el mes de abril de 1982, el Plan Siderúrgico y la necesaria voluntad política aludida en él de proteger la industria no aparece por ningún lado. Más de 300 mil toneladas de productos siderúrgicos que son objeto de fabricación nacional fueron importadas durante $1981^{51}$.

Así las cosas, la dirigencia de FEDEMETAL manifestó las malas condiciones del comercio internacional, en contravía de las intencionalidades del PIIS, pues

[...] entre otras problemáticas del comercio mundial del acero, se encontraban significativas expansiones siderúrgicas efectuadas en los últimos veinte años en el Japón y países de la Comunidad Económica Europea, sobresaturación del mercado mundial del acero, el dumping, la venta a precios de costo e incluso inferiores a él y prácticas comerciales irregulares ${ }^{52}$.

Frente a estas situaciones de presión competitiva sobre el sector siderúrgico mundial, tanto la Comunidad Económica Europea como los Estados Unidos aplicaron medidas de protección frente a la invasión de aceros baratos, tales como el plan Davignon y el Trigger Price Mechanism, respectivamente ${ }^{53}$; medidas que quitaron validez al libre comercio, pues a medida que el comercio internacional se expandía, los países establecían trabas, subsidios, líneas especiales de crédito para las ventas en el exterior, e inclusive cuotas y prohibiciones para la entrada de productos, sobre todo para los provenientes del tercer mundo. Ante estas circunstancias, el gremio reclamaba que países como Colombia debían proteger sus propios mercados y exportaciones en una época en la que el resto del mundo cerraba sus fronteras ${ }^{54}$. Así, de nuevo el sector pedía la protección de la industria nacional por parte del Estado, tal como lo había hecho hacia la década de 1940; mientras tanto este, a través de la venta de sus acciones en Paz del Río a ciudadanos y trabajadores de la misma fábrica, partió su participación en la empresa y

$51 \quad$ Orduz, «La siderúrgica colombiana...», 23.

52 Orduz, «La siderúrgica colombiana...», 23.

53 Orduz, «La siderúrgica colombiana...», 23.

54 P. Beltz, «Objetivos y estrategias del desarrollo industrial», Carta Metalúrgica, 357 (1983): 15. 
fue desmontando los beneficios tributarios que favorecían al sector.

\section{FEDEMETAL y su participación en la política pública del sector}

La industrialización del país expresó la maduración de su élite empresarial, contexto en el que se comprende la creación de FEDEMETAL en 1955, como entidad que surgió independiente de la Asociación Nacional de Industriales -ANDI- (fundada en 1944). FEDEMETAL se conformó debido al descontento de los industriales metalmecánicos con la falta de reconocimiento de sus intereses específicos en la Asociación, cuya orientación partidista hacía que desviaran su atención de aspectos importantes como la creación de comités especializados para cada sector industrial. Otro elemento que explica la creación de FEDEMETAL fue la creciente importancia que logró hacia los años de 1950 el sector metalmecánico, la que no era reconocida en la ANDI, pues en esta pesaban más los intereses de los productores de bienes de consumo masivo como textiles y alimentos. Era claro entonces que los productores de bienes de capital tenían necesidades distintas y hasta opuestas a las de los productores de bienes de capital lo cual ameritaba la creación de un gremio especializado como FEDEMETAL ${ }^{55}$.

Inicialmente el mecanismo a que más acudieron gremios como FEDEMETAL, fue el lobby o cabildeo ante los funcionarios oficiales para la presentación y aprobación de proyectos legislativos que los beneficiaran. Así lo hicieron por medio de comunicaciones, estudios sectoriales y la publicación de Carta Metalúrgica, plataforma de controversia con el gobierno y mecanismo de interlocución y opinión sectorial. La participación del gremio en las políticas públicas se evidenció en tres líneas de trabajo: en su primera etapa vivió una fuerte dinámica de análisis y pronunciamiento en la política industrial, luego se dedicó a una intensa labor de actualización tecnológica y a la generación de información estadística del gremio; finalmente se dio una reestructuración

55 De La Pedraja, Fedemetal y la industrialización..., 45-46. 
de la institución con una dedicación más introspectiva sobre el desarrollo del sector ${ }^{56}$.

FEDEMETAL reclamaba del Estado una visión de largo plazo como responsabilidad de la clase política, que debería ejecutarse con criterios técnicos e información estadística en un medio donde "priman los conceptos políticos» y la incertidumbre ${ }^{57}$, declaraciones que expresan la filosofía racional y tecnocrática del empresariado muy propio de un tipo de empresas cuyos ingentes inversiones y mercados correspondían a grandes industrias con periodos de recuperación de largo plazo. Sin embargo, desde temprano el gremio consideró que el fortalecimiento del sector industrial no debería depender únicamente del Estado, sino de un trabajo conjunto, según lo expresó en 1968 su presidente, Alberto Devia:

La finalidad propulsora del Estado en la industrialización coincide con el papel, bien entendido del empresario privado. Corresponde al Estado moderno la planeación indicativa del sector industrial. Pero la planeación, para ser efectiva, debe conocer los propósitos de los sectores a que se aplica y la realidad objetiva de estos (...) Es objetivo primordial de la industria de hoy la búsqueda del autoabastecimiento de divisas, para que no dependa de las generadas por otras fuentes, como las agrícolas. Objetivo a largo plazo que solo podrá alcanzarse por el esfuerzo tenaz y conjunto del Estado y de los particulares ${ }^{58}$.

Hacia 1976 se desató una controversia entre FEDEMETAL y el gobierno de Alfonso López Michelsen (1974-1978) por la desventajosa participación de Colombia en el Pacto Andino. La posición gremial fue criticar la relativa apertura económica implementada por el Estado, pues se trataba de una industria sin el dispositivo tecnológico y financiero para soportar la competencia internacional, que además pasaba por una coyuntura de crisis mundial de los

56 Alberto Devia, "Apartes del discurso del presidente de Fedemetal», Carta Metalúrgica, 300 (1968): 8-13.

57 FEDEMETAL, «La intervención estatal...», 23.

58 Devia, "Apartes del discurso...», 8. 
precios del hierro y del acero ${ }^{59}$. Hay que aclarar que hacia mediados de la década de 1970, se había presentado la crisis económica mundial (derivada de la del petróleo de 1973 y de la menor demanda de bienes de capital) y en especial en la industria siderúrgica, lo que explica la desindustrialización del sector. Esta significaba una baja en la demanda del 30\% y de los precios del 50\%, había un excedente de capacidad instalada en los países industrializados y su restructuración presionaba por el uso de nuevos aceros livianos y más resistentes, lo que dejaba rezagada gran parte de la capacidad instalada en el sector ${ }^{60}$. Este contexto de dificultades confluyó con un «cansancio industrial» nacional que venía de los años sesenta pero que fue más evidente hacia los setenta, debido a factores como el "desmonte de la estrategia sustitutiva" con las reformas de la administración del presidente Alfonso López (1974-78) ${ }^{61}$. En este contexto el presidente del gremio, Fernando Sanz (1976), denunció la problemática del sector al señalar las violaciones a normas y compromisos del Pacto y la amenaza de la entrada de Venezuela al mismo, que por ser considerada una potencia industrial y financiera en la región, implicaba una seria desventaja para Colombia. Dirigentes de FEDEMETAL manifestaron su oposición al cambió en la política de sustitución de importaciones, planteada en el Plan de Desarrollo "Para cerrar la brecha" del presidente López, al calificar de "errónea» la política de expansión de la producción de bienes de consumo y no la de la industria básica y la de fabricación de bienes y equipo, y argumentaron que la primera no era una buena opción para la generación de empleo por unidad productiva mientras que la segunda sí $^{62}$. López señaló que no tenía por qué reinar el pesimismo frente a la integración regional y aclaró que la política del gobierno

59 De La Pedraja, Fedemetal y la industrialización..., 66-69.

60 M. Landa y Andrés Solari, «La industria siderúrgica latinoamericana en perspectiva", Revista de la Facultad de Economía Vasco de Quiroga, (S.F.): 3-4. Acceso el 23 de junio de 2012, http://www.economia.umich.mx/eco_old/publicaciones/ EconYSoc/ES12_05.html.

61 Como la reducción de la inversión estatal en la industria y de los créditos a largo plazo, la paulatina liberación de importaciones, la reducción de las tarifas arancelarias, menos incentivos fiscales frente a la tasa de devaluación y los pobres resultados de la integración andina.

62 FEDEMETAL, «La opinión de Fedemetal», Carta Metalúrgica, 335 (1976 b): 26. 
era buscar la eficiencia industrial dentro de una limitación de recursos, en un contexto en el que tanto en Europa como en Estados Unidos se hablaba de una recesión mundial, que Colombia no tenía que temer.

Aunque el Pacto Andino buscaba la complementariedad entre las economías de los países del área, tenía serias limitaciones. Así se concluyó en un seminario celebrado en agosto de 1977 en Cartagena, por parte del sector con objeto de analizar el Programa Metalmecánico. Allí se reconoció el clima de desconfianza empresarial para impulsar las asignaciones debido al incumplimiento de las decisiones, la ausencia de estadísticas regionales que impedían evaluar los resultados del programa, el incumplimiento de la Decisión 57, por parte de los países miembros lo que hacía apremiante la creación de un Órgano Jurisdiccional del Acuerdo, la carencia de un estatuto de compras oficiales a nivel subregional que disminuía la efectividad de las asignaciones y el hecho de que las concesiones otorgadas en el marco de la Asociación Latinoamericana de Libre Comercio (ALALC) vulneraban la efectividad de las asignaciones ${ }^{63}$. De igual forma los empresarios veían la inestabilidad política, la heterogeneidad productiva y de inversiones, la complejidad de las comunicaciones del área y las diferencias de tecnología nacionales como problemáticas para la integración ${ }^{64}$. De todos modos gremio y gobierno coincidían en la necesidad de una planeación indicativa para la industria siderúrgica, lo que se expresó en un trabajo conjunto durante las sesiones del Consejo de Política Económica y Social para la elaboración del plan de desarrollo ${ }^{65}$ y en la participación de FEDEMETAL en el PIIS, en coautoría con el Departamento Nacional de Planeación y del IFI. En medio de la crisis de la industria textil, la vocación de la economía nacional se reorientaba parcialmente hacia las industrias extractivas mineras, lo que se evidenció hacia 1971, pues dentro del grupo andino Colombia poseía las mayores reservas carboníferas (40.000 millones-tons.) que superaban

63 Mauricio Guerrero, Diez años del Grupo Andino (Bogotá: CIID, 1980), 372.

64 J.J. Rizo, «El Nacionalismo económico y el Pacto Andino», Carta Metalúrgica, 334 (1976): 15.

65 L. López, «Desarrollo Siderúrgico», Carta Metalúrgica, 334 (1976): 37-40. 
las de hierro ${ }^{66}$, por lo que sus mayores ventajas competitivas se orientaban a la exportación de coque y/o carbón coquizable y se analizaba el posible establecimiento de una siderúrgica integrada localizada en la Costa Atlántica que aprovechase el coque nacional derivado del mineral importado, procesado de tal manera que se incrementara la producción de acero nacional ${ }^{67}$. En consonancia con ello, a finales de la década de 1970, el gobierno implementó una estrategia de desarrollo industrial integrada y coherente para fortalecer la industria colombiana, entre las que se destacan: la Ley 20 de 1978, que dio paso a importantes incentivos a la capitalización del sector privado, el fortalecimiento de la capacidad financiera del IFI y su conversión en banco de redescuento para agilizar su operación, el surgimiento de los parques industriales y de sociedades de comercialización para impulsar el comercio exterior, el adelanto del plan indicativo de la industria siderúrgica, la explotación del carbón del Cerrejón, del níquel en Cerromatoso, del papel con la constitución de Papelcol y de hierro esponja producido por Ferrominera ${ }^{68}$. De todos modos la posición de FEDEMETAL fue reiterativa en cuanto a la necesidad de que el Estado protegiera la industria con mecanismos de regulación de precios y protección arancelaria. $\mathrm{Al}$ respecto, una de las contribuciones de la agremiación a la formulación de la política pública del sector fue la presentación de una nueva plataforma industrial al gobierno nacional, a

66 Hacia la década de 1940 las misiones geológicas de los municipios de Paz del Río, Tasco, Socotá y Sativasur arrojaron los siguientes resultados: reservas de hierro probadas, probables y posibles 103’147.600 ton. Por su parte, las reservas de carbón, con área de $400 \mathrm{~km}^{2}$ y que tenían como eje la vía férrea Sogamoso - Paz del Río, se calcularon en 1.900`000.000 de toneladas y se estimó que buen parte del carbón era de 7000 a 8000 calorías, apto para ser coquizable y utilizable para la industria siderúrgica. Las calizas, vecinas a los yacimientos de hierro y carbón, se calcularon en 65 millones de toneladas. Hacia mediados de 1970 la dotación de recursos minerales de hierro y acero en el municipio de Paz de Río se estimaba en reservas totales de 26 millones de toneladas reales y 40 millones probables. El carbón coquizable existente en el resto de la región, era suficiente para atender las siderúrgicas integradas del país y aun para la exportación. Adicionalmente, la nación contaba con caliza y la disponibilidad de gas en la Guajira lo que abría importantes perspectivas para procesos de reducción directa y producción de hierro esponja, que complementarían la producción de Acerías Paz de Río (FEDEMETAL, 1976, p. 27).

67 Instituto de Fomento Industrial [IFI], Planeación indicativa de la industria Siderúrgica Nacional. La Industria Siderúrgica Nacional frente al Grupo Andino (Bogotá, Colombia: IFI, 1971), 88-91.

68 FEDEMETAL, «La intervención estatal...», 21. 
partir de la cual se desarrollaría un estudio de la industria del acero y del hierro con objeto de identificar la capacidad de producción y las necesidades prioritarias nacionales para un adecuado abastecimiento de las materias primas básicas y del desarrollo metalmecánico y siderúrgico.

\section{Acerías Paz del Río y el surgimiento de siderúrgicas privadas}

Hacia la década de 1960 la materia prima fabricada por Paz del Río facilitó el surgimiento de diferentes empresas metalmecánicas subsidiarias: fábricas de alambres, mallas, clavos, tornillos, tuercas, estructuras, marcos y accesorios para ventanas, y toda la gama de carpintería metálica. Como ya se indicó, para entonces existía la Siderúrgica Corradine (1934), la Siderúrgica de Medellín(1938) y del Muña (1947) en Bogotá y una variedad de talleres y pequeñas fábricas, de modo que para mediados del siglo XX Colombia contaba con una modesta y emergente industria siderúrgica y metalmecánica. La situación de interdependencia entre estas empresas se hacía evidente con cualquier proyecto de ampliación industrial que se emprendiera, pues la disponibilidad de hierro puro en Colombia era muy limitada, así como la disposición de chatarra para ser procesada por las siderúrgicas semintegradas privadas, lo que significa que Paz del Río no solo abastecía el mercado comercial de la construcción y de las industrias, sino que proveía la materia prima para las demás siderúrgicas del país, desbordadas por la creciente demanda nacional.

La década de 1960 se cerró con una capacidad instalada de 530.000 toneladas/año para producir acero crudo, y 950.000 toneladas/año en trenes de laminación, en mezcla de productos terminados planos en caliente, sin contar la producción de la industria militar. Esta capacidad correspondía a la siderurgia integrada Acerías Paz del Río y a las nuevas semintegradas que conformaron la cadena productiva del sector: Siderúrgica del Pacífico (1961), Siderúrgica de Boyacá S.A. (1961), Siderúrgica del Norte (1965), Aceros Ramson (1966), Heliacero (1968), Acerías de Colombia(1970), Distribuidora de Aceros Colombianos (1972), Aceros Boyacá (1979), Laminados 
Andino (1980) y Acerías Sogamoso (1981). Así, para los años de 1980 se había constituido una decena de empresas que duplicaron las existentes durante la primera mitad del siglo XX. Sin embargo, el desarrollo siderúrgico colombiano, base de su desarrollo metalmecánico, distaba mucho de los índices regionales de Latinoamérica, una característica del conjunto industrial colombiano ${ }^{69}$.

La capacidad de producción nacional estaba limitada por la poca disponibilidad de chatarra y del bajo nivel de producción de Paz del Río frente a las necesidades en aumento de las nuevas siderúrgicas semintegradas, de modo que la mayor parte de la producción nacional de aceros se destinaba al sector de la construcción y de obras civiles, el resto era adquirido por la industria metalmecánica, y aun así el 55\% del consumo nacional debía ser importado ${ }^{70}$. Así las cosas, «la producción efectiva del acero de Paz del Río era del 86\% en promedio y del $50 \%$ en las plantas semintegradas debido a la ya mencionada escasez de desechos de hierro reutilizables, suplidos con importaciones de palanquilla y chatarra ${ }^{71}$. Pero las dificultades del sector iban más allá de la dependencia externa de materias primas, insumos y equipos para sus ampliaciones, pues también implicaba la escasez de capital de trabajo, la irregularidad de los medios de transporte en una geografía fragmentada y la falta de una política estatal que organizara la eficiencia industrial en su conjunto ${ }^{72}$.

Las necesidades de infraestructura, los requerimientos de energía eléctrica, la explotación eficiente de los yacimientos carboníferos, la utilización del gas para la reducción directa,

69 FEDEMETAL, «Hacia una infraestructura industrial», Carta Metalúrgica, 335 (1976a): 9. «Mientras que la producción de acero en 1974 era en Argentina 2.3 millones de toneladas; en Chile 635 mil toneladas; México 5 millones; Venezuela 1.0 millones. En Colombia alcanzaba solo un poco más de 300 mil toneladas anuales producidas por las empresas semintegradas de carácter privado y 230.000 de Acerías Paz del Río, la única de proceso integrado, lo cual significa el nivel de producción per cápita más bajo de América del sur, exceptuando Bolivia».

70 FEDEMETAL, «Hacia una infraestructura...», 9.

71 Sandoval, R. «Opinión Empresarial: Metalúrgica Boyacá S.A.» Carta Metalúrgica 337 (1977): 11.

72 Gutiérrez, «La industria metalúrgica...», 56-60. 
la localización estratégica y la explotación de calizas y otros minerales necesarios en los procesos productivos, en lo que se expresaba la necesidad de ampliación de la capacidad productiva siderúrgica nacional, todos retos difíciles de salvar para atender las restricciones del comercio internacional de hierro y acero que se presentaron entre 1974 y 1980. Frente a esta situación, el citado informe Dastur sirvió de base para reestructurar el sector y prepararlo para atender los retos internos y del comercio exterior, debido a los pobres resultados de integración del Pacto Andino. Según el informe «el consumo de acero crecía en armonía con el desarrollo urbanístico del país y la producción interna debería incrementarse de acuerdo con los programas del gobierno, con el ensanche de la capacidad de la planta integrada hasta alcanzar un millón de toneladas anuales y se debía instalar una planta de reducción directa para producir 380 mil toneladas de hierro esponja para las siderúrgicas semintegradas como complemento de la chatarra» ${ }^{73}$.

Como se ha expuesto, al finalizar la década de 1970 se inició en Colombia una segunda oleada de creación de nuevas empresas siderúrgicas privadas con la expectativa de restablecer el sector, sin embargo, la fuerte crisis económica de inicios de la década de 1980 y la baja capacidad de producción nacional en relación con el mercado suramericano, dieron al traste con tal programa. Para entonces la desindustrialización de la economía se explica por la liberalización de las importaciones (reducción de aranceles, liberalización del régimen de licencias y rebaja de los incentivos a las exportaciones) que debilitaron sectores de la industria en proceso de consolidación en el mercado nacional. El fracaso de este tipo de medidas más los efectos de la crisis mundial, supuso el ya conocido desajuste externo y una profunda crisis financiera ${ }^{74}$. En este panorama la producción de aceros terminados en Colombia era aproximadamente de 350 mil toneladas, mientras el consumo aparente nacional se estimaba en 800 mil toneladas. El reto era claro, llegar

73 FEDEMETAL, «Hacia una infraestructura...», 9.

74 Garay, Estructura industrial e..., 459. 
a producir el acero que requería el país en un contexto de evidente atraso de la industria nacional respecto de otros del área, pues la producción de acero per cápita colombiana (15 $\mathrm{Kg} / \mathrm{pc}$ ) era superada con creces por la industria argentina (129 $\mathrm{Kg})$, brasileña $(125 \mathrm{Kg})$, chilena $(65 \mathrm{Kg})$, mexicana $(110 \mathrm{Kg})$, peruana $(26 \mathrm{Kg})$ y venezolana $(109 \mathrm{Kg})^{75}$. Estos son indicios de la fuerte presión que ejercían las industrias del Pacto Andino sobre los precios y la demanda interna colombiana, cuyas modernas plantas habían logrado considerables niveles de eficiencia ${ }^{76}$. Frente a estas circunstancias, FEDEMETAL estableció nuevos lineamientos para el sector entre 1983 y 1986, lo que implicaba que el gremio reclamara de nuevo la intervención protectora del Estado, demanda que no tuvo el mismo eco que en la década de 1940 en la dirigencia nacional, pues para entonces se privilegiaba la eficiencia industrial nacional, se consolidaban nuevos bloques económicos y las políticas de puertas abiertas al comercio internacional, lo que no significa que el Estado dejara de regular e intervenir la economía, sino que en adelante lo hiciera bajo los nuevos marcos de la competitividad nacional e internacional, es decir bajo directrices neoliberales.

\section{Conclusiones}

La exposición anterior permite concluir que el Estado colombiano jugó un papel de primer orden en el proceso de sustitución de bienes duraderos y de capital con la industria siderúrgica y metalmecánica desde finales de la década de 1930 hasta los años de 1980. Ello implicó el desarrollo de toda una infraestructura institucional que expresó la consolidación misma del Estado moderno como un ente burocrático centralizado, que legitimaba los intereses de la clase empresarial en la política pública y con ello la configuración de un modesto capitalismo industrial nacional. Si se consideran los procesos de industrialización de México, Brasil y Argentina, el desarrollo del sector siderúrgico colombiano ha sido tardío y muy incipiente, no obstante las transformaciones tan

$75 \quad$ Orduz, «La siderúrgica colombiana...», 24.

76 C. Navarro, «Industria Siderúrgica un sector en recuperación», Carta Metalúrgica, 361 (1985): 13. 
trascendentales que ello supuso para el país en un contexto de vertiginosa urbanización, desarrollo de la infraestructura vial, la emergencia de clases medias urbanas con capacidad de consumo, la consolidación del mercado nacional y la integración de Colombia al capitalismo occidental.

Coincidente con el planteamiento de Ocampo, los hallazgos investigativos expuestos son evidencia de que el ordenamiento constitucional y la planeación han sido expresiones del dirigismo estatal en Colombia desde la segunda posguerra, mediante la intervención directa que constituye al Estado en empresario y la regulación macroeconómica que reglamenta las actividades de agentes privados. Ambos mecanismos se concretaron en los planes de gobierno, la gestión del IFI, el papel crediticio y cambiario del Banco de la República, y el reconocimiento de los intereses gremiales en las políticas públicas por medios jurídico políticos como las compras estatales, alternativas de financiamiento, las exenciones de impuestos a empresas nacionales, la estructura arancelaria y el control a las importaciones de equipos y bienes de capital. Estos dos últimos han sido destacados por Ocampo ${ }^{77}$ como esenciales para el crecimiento y la diversificación industrial y con ello recuerda que desde los años de 1960 se desvirtuaron las acusaciones que se hacían al Estado colombiano por promover una industria nacional «artificial» e ineficiente, es decir, excesivamente protegida. Para entonces el estudio de Thomas Lee Hutchenson mostró que a diferencia de otros países latinoamericanos, la industria colombiana en su conjunto no estaba excesivamente protegida (y así lo ha afirmado Kalmanovitz), que usaba un margen bajo de dicha protección y que "la industria del hierro y del acero y la de productos metálicos estaban moderadamente protegidas $(40-55 \%) \gg^{78}$.

La instauración de Paz del Río hacia los años de 1940 y dos décadas después la creación del conjunto de industrias semintegradas que procesaban sus materias primas, marcó

77 Ocampo, Historia económica..., 275.

78 Ocampo, Historia económica..., 275. Kalmanovitz, Economía y nación..., 307 308. 
un hito en la historia de la industria colombiana y del Departamento de Boyacá, y tuvo lugar en una coyuntura política y económica que priorizaba el nacimiento de industrias nacionales como proyecto político y económico convergente con el Estado empresario, salvaguarda de la "soberanía económica» nacional. De acuerdo con la hipótesis planteada, ello evidenció la aceleración del proceso de modernización que vivía Colombia desde la década de 1930 y la superación del modelo de sustitución de importaciones por el modelo exportador hacia los años de 1980.

La formación del sector es expresión de la madurez del gremio y de la clase industrial, que tuvo una alta participación en su proceso de consolidación a través de la fuerza gremial de la ANDI y en particular de FEDEMETAL. En su primera etapa de gestión representativa este gremio tuvo un activo papel con las entidades estatales encargadas del proteccionismo industrial, después de los procesos de apertura con el Pacto Andino, la agremiación se reorientó a prestar servicios a las industrias que facilitaran la formación de personal especializado y la transferencia de tecnologías para mejorar su nivel de productividad, sin dejar de intervenir en las nuevas dinámicas de competitividad internacional del sector.

Se quedan varias preguntas abiertas que podrían ser importantes para continuar en nuevos procesos de investigación, tales como la interrelación del sector siderúrgico con otros sectores industriales que compartieron el mismo marco regulatorio, a lo largo del siglo XX. De igual modo, el papel de los gobiernos y políticas departamentales y locales en la operacionalización o en el sostenimiento de las industrias nacionales que en un momento dado aceleraban procesos sociales como las migraciones con origen laboral o las nuevas formaciones urbanas, y que posteriormente quedaban bajo la directriz de los gobiernos departamentales sin el mismo apoyo estatal.

También es interesante abordar los flujos de conocimiento y tecnología nacionales e internacionales que se 
requerían para el montaje de grandes empresas que exigían tecnologías nuevas para su época, y demandaban grandes inversiones y conocimiento especializado. Particularmente la siderurgia en Colombia contó desde sus primeras experiencias en las ferrerías del siglo XIX en Antioquia Cundinamarca y Boyacá con la influencia de ingenieros Franceses, Alemanes e ingleses, pero en su posterior desarrollo fueron muchos empresarios nacionales los que importaron directamente maquinarias de USA y debían crear sus propios medios de adaptación tecnológica para poner en funcionamiento las maquinas a las condiciones locales, lo que evidencia un fuerte flujo de interacción y creación de conocimientos que no ha sido abordado como objeto de estudio y que puede ser relevante para otras experiencias industriales actuales.

\section{Fuentes documentales}

Beltz, P. «Objetivos y estrategias del desarrollo industrial». Carta Metalúrgica 357 (1983): 15.

Botero, M. «El sector desatendido». Carta Metalúrgica 334 (1976): 48-49.

Congreso de Colombia «Ley 45/1947, de 15 de diciembre, por la cual se crea la Empresa Siderúrgica Nacional de Paz de Río, se provee a su financiación y se dan autorizaciones al Gobierno y al Instituto de Fomento Industrial».

Departamento Nacional de Planeación (DNP). Bogotá-Colombia. Documento CONPES. 1968.

Departamento Nacional de Planeación (DPN). Bogotá-Colombia. Alternativas de Desarrollo del Sector Siderúrgico-Informe Dastur, DNP-1.344-UEI-IE, 1. 1976.

Departamento Nacional de Planeación (DNP). Bogotá-Colombia. Plan Indicativo de la Industria Siderúrgica, DNP-1 1609, 9-12. 1979

Devia, Alberto. «Apartes del discurso del presidente de Fedemetal». Carta Metalúrgica 300 (1968): 8-13. 
FEDEMETAL. «Hacia una infraestructura industrial». Carta Metalúrgica 335 (1976a): 7-9.

FEDEMETAL. «La opinión de Fedemetal». Carta Metalúrgica 335 (1976 b): 25-26.

FEDEMETAL. «Evolución y perspectivas del modelo colombiano de industrialización». Carta Metalúrgica 347 (1980a): 41-56.

FEDEMETAL. "La intervención estatal de un peso muerto». Carta Metalúrgica 385 (1980b): 21-23.

Gerlein, Roberto. «Estímulos a la actividad industrial». Carta Metalúrgica 352 (1982): 9-10.

Gutiérrez, J. «La industria metalúrgica y metalmecánica frente al sector externo». Carta Metalúrgica 334 (1976): 56-60.

«La explotación de Paz del Río no es solo posible sino necesaria». El Tiempo, Bogotá, 11 de junio de 1948.

López, L. «Desarrollo Siderúrgico». Carta Metalúrgica 334 (1976): $37-40$.

Méndez, M. «El papel potencial del sector metalúrgico». Carta Metalúrgica 337 (1977): 31.

Navarro, C. «Industria Siderúrgica un sector en recuperación». Carta Metalúrgica 361 (1985): 12-13.

Orduz, M. «La siderúrgica colombiana: un patrimonio nacional». Carta Metalúrgica 352 (1982): 23-24.

Rizo, J. J. «El Nacionalismo económico y el Pacto Andino». Carta Metalúrgica 334 (1976): 15.

Sandoval, R. «Opinión Empresarial: Metalúrgica Boyacá S.A.». Carta Metalúrgica 337 (1977): 1.

«Se pide exonerar de impuestos a la Industria en Boyacá». El Tiempo, Bogotá, 03 de mayo de 1976. 


\section{Bibliografía}

Amézquita, Pascual. «La política de sustitución de importaciones en el contexto colombiano». Revista Globalización, Competitividad $y$ Gobernabilidad, $\mathrm{n}^{\circ} 2$ (2010): 50.

Anderson, Perry. El estado absolutista. México: Siglo XXI Editores, 1982.

Bejarano, Jesús Antonio. «La economía colombiana entre 1946 y 1958». En Historia de Colombia tomo V, editado por Álvaro Tirado Mejía, 149-166. Bogotá: Planeta, 1989.

Bértola, Luis., y José Ocampo. El desarrollo económico de América Latina desde la independencia. México: Fondo de Cultura Editores, 2013.

Corchuelo, Alberto., y Gabriel Misas. «El proceso de industrialización colombiano 1945/1958». Revista uno en dos, nº 4 (1975): 48-86.

De La Pedraja, René. Fedemetal y la industrialización de Colombia. Bogotá: Bogotá Fedemetal 1986.

Federación Nacional de Cafeteros. Compilación Cafetera 1939-1951. Bogotá: Editorial Argra, 1951. Recuperado de: http://ufdc.ufl. edu/UF00076974/00001/4j.

Garay, Luis. Estructura industrial e internacionalización en Colombia. 1967-1996. Santafé de Bogotá: Departamento Nacional de Planeación, 1998.

Gaviria, Juan. «La economía colombiana. 1858-1970». En Nueva Historia de Colombia tomo $V$, editado por Álvaro Tirado Mejía, 167-188. Bogotá: Planeta, 1989.

Guarín, Álvaro y Franco, Daniel. «La sustitución de importaciones como medio para un desarrollo sostenible». Revista Universidad EAFIT 44, n 151 (2008): 56-57.

Guerrero, Mauricio. Diez años del Grupo Andino. Bogotá: CIID, 1980. 
Hobsbawn, Eric. Naciones y nacionalismo desde 1870. Barcelona: Crítica, 2000.

Instituto de Fomento Industrial [IFI]. Planeación indicativa de la industria Siderúrgica Nacional. La Industria Siderúrgica Nacional frente al Grupo Andino. Bogotá: Colombia, 1971.

Kalmanovitz, Salomón. Nueva historia económica de Colombia. Bogotá, Colombia: Taurus, 2010.

Kalmanovitz, Salomón. Economía y nación. Una breve historia económica de Colombia. Bogotá: Grupo Editorial Norma, 2003.

Landa, M., y Andrés Solari. «Laindustria siderúrgica latinoamericana en perspectiva». Revista de la Facultad de Economía Vasco de Quiroga, S. F. Recuperado de: http://www.economia.umich. $\mathrm{mx} /$ eco_old/publicaciones/EconYSoc/ES12_05.html.

Lopera, M. El desarrollo de la Industria Metalmecánica Colombiana hasta 1970. Medellín: Centro de Investigaciones Económicas Universidad de Antioquia, 1983.

Martínez, Astrid. La Estructura arancelaria y las estrategias de industrialización en Colombia 1950-1982. Bogotá: Universidad Nacional de Colombia. Centro de Investigaciones para el desarrollo, 1989.

Mayor Mora, Alberto. «Historia de la industria colombiana. 18861930». En Nueva Historia de Colombia tomo V, editado por Álvaro Tirado Mejía, 313-332. Bogotá: Planeta, 1989.

Misas, Gabriel. «De la sustitución de importaciones a la apertura económica. La difícil consolidación industrial». En Desarrollo económico y social en Colombia, Siglo XX, editado por Gabriel Misas, 111-134. Bogotá: universidad Nacional de Colombia, 2001.

Ocampo, José., ed. Historia económica de Colombia. Bogotá, Colombia: T.M. Editores \& Fedesarrollo, 1994. 
Poveda, Gabriel. Políticas económicas, desarrollo industrial $y$ tecnología en Colombia, 1925-1975. Bogotá: Editora Guadalupe, 1979.

Silva, A., y T. Caldas. Régimen Legal de la Industria en Colombia. Bogotá: Minerva Ltda., 1956.

Tilly, Charles. Coerción, capital y estados europeos, 990-1990. Madrid: Alianza Editorial, 1992.

\section{Citar este artículo:}

Barreto Bernal, Patricia Carolina., y Juan Carlos Jurado Jurado. «El papel del Estado colombiano en la conformación del sector siderúrgico de Boyacá. 1938-1980». Historia $Y$ MEMORIA, $\mathrm{n}^{\circ} 15$ (2017): 203-242. DOI: https://doi. org/10.19053/20275137.n15.2017.5568 